\title{
Sexual Abuse: A Journal of Research and Treatment
}

\section{Assessing Sexual Interest in Children Using the Go/No-Go Association Test}

\begin{tabular}{|c|c|}
\hline Journal: & Sexual Abuse: A Journal of Research and Treatment \\
\hline Manuscript ID & SA-16-01-008.R2 \\
\hline Manuscript Type: & Original Research Article \\
\hline Keywords: & $\begin{array}{l}\text { Go/No-Go Association Task, indirect measure, sexual interest, Sexual } \\
\text { Offender, sexual fantasy }\end{array}$ \\
\hline Abstract: & $\begin{array}{l}\text { The present study investigated whether a latency-based Go/No-Go } \\
\text { Association Task (GNAT) could be used as an indirect measure of sexual } \\
\text { interest in children. A sample } 29 \text { individuals with a history of exclusive } \\
\text { extrafamilial offenses against a child and } 15 \text { individuals with either a } \\
\text { history of exclusive intrafamilial or mixed offenses (i.e., against both adults } \\
\text { and children) were recruited from a treatment center in the US. Also, a } \\
\text { sample of } 26 \text { non-offenders was recruited from a university in the UK. All } \\
\text { participants completed the Sexual Fantasy-GNAT, a Control-GNAT, and two } \\
\text { self-report measures of sexual fantasy. It was hypothesized that, relative } \\
\text { to the two comparison groups, the extrafamilial group would respond faster } \\
\text { on the block that paired 'sexual fantasy' and 'children'. Also, GNAT scores } \\
\text { were expected to correlate with child-related sexual fantasies. Support was } \\
\text { found for both hypotheses. Response-latency indices were also found to } \\
\text { effectively distinguish the extrafamilial group, as well as those who self- } \\
\text { reported using child-related sexual fantasies. The implications of these } \\
\text { findings, along with the study's limitations and suggestions for future } \\
\text { research, are discussed. }\end{array}$ \\
\hline
\end{tabular}

\section{SCHOLARONE \\ Manuscripts}


RUNNING HEAD: ASSESSING SEXUAL INTEREST IN CHILDREN USING THE GNAT

\author{
Assessing Sexual Interest in Children \\ Using the Go/No-Go Association Test
}




\title{
ASSESSING SEXUAL INTEREST IN CHILDREN USING THE GNAT
}

\begin{abstract}
The present study investigated whether a latency-based Go/No-Go Association Task (GNAT) could be used as an indirect measure of sexual interest in children. A sample 29 individuals with a history of exclusive extrafamilial offenses against a child and 15 individuals with either a history of exclusive intrafamilial or mixed offenses (i.e., against both adults and children) were recruited from a treatment center in the US. Also, a sample of 26 nonoffenders was recruited from a university in the UK. All participants completed the Sexual Fantasy-GNAT, a Control-GNAT, and two self-report measures of sexual fantasy. It was hypothesized that, relative to the two comparison groups, the extrafamilial group would respond faster on the block that paired 'sexual fantasy' and 'children'. Also, GNAT scores were expected to correlate with child-related sexual fantasies. Support was found for both hypotheses. Response-latency indices were also found to effectively distinguish the extrafamilial group, as well as those who self-reported using child-related sexual fantasies. The implications of these findings, along with the study's limitations and suggestions for future research, are discussed.
\end{abstract}

Keywords: Go/No-Go Association Task, indirect measure, deviant sexual interest, sexual offender, sexual fantasy 
Assessing Sexual Interest in Children Using the Go/No-Go Association Test Sexual interest has been defined as the predisposition to respond sexually to a preferred category (i.e., type of person, object, or activity) (Rullo, Strassberg, \& Israel, 2010). This can include 'deviant' categories, such as children. A sexual interest in children is regarded as an important factor in the etiology of sexual offending (Ward \& Beech, 2006), and has been shown to be a risk factor associated with sexual recidivism (Hanson \& MortonBourgon, 2005). In light of this, researchers and clinicians have devoted a great deal of effort into developing effective methods of assessing sexual interest in children.

\section{Objective sexual arousal (i.e., the physiological response towards a target of sexual} interest) is considered to be an indicator of sexual interest (Chivers, 2005). As a result, genital

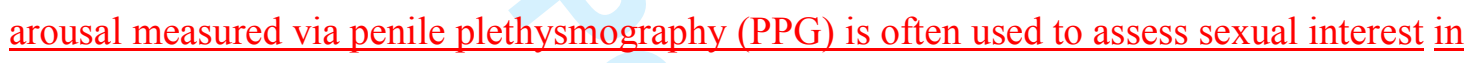

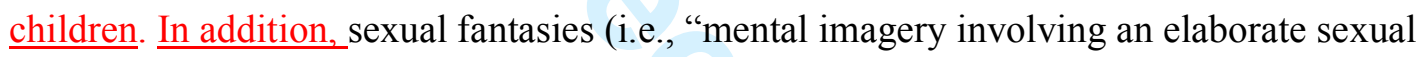
scenario or script”; Bartels \& Gannon, 2011, p.553) are thought to generally express one's sexual interest (Chivers, 2005). Indeed, individuals with a sexual offense against a child (ISOCs) who report using sexual fantasies involving children also self-report a sexual interest in children (Stinson \& Becker, 2008)). Thus, self-report measures of sexual fantasy are also used as an assessment tool (Allan, Grace, Rutherford, \& Hudson, 2007; Beggs \& Grace, 2011; Hudson, Wales, Bakker, Ward, 2002; Gannon, Terriere, \& Leader, 2012).

Although self-report and PPG have contributed a great deal to both the empirical literature and clinical practice, they suffer from some procedural problems (Kalmus \& Beech, 2005). For example, self-report is susceptible to socially desirable responding, while PPG is an intrusive procedure. As a result, researchers have become interested in exploring the adaptation of socio-cognitive measures to indirectly assess deviant sexual interests (Thornton \& Laws, 2009). Self-report measures require participants to deliberately respond to statements/items related to a sexual interest, with such responses taken as a direct indication 
of one's level of interest. Indirect measures, on the other hand, typically require participants to respond to a task that produces an outcome (e.g., response-latencies) that can be used to infer one's level of sexual interest. Thus, given their indirect nature, indirect measures are believed to be less intrusive and less affected by socially desirable responding (Snowden, Craig, \& Gray, 2011).

A widely used indirect measure is Viewing Time (VT). Here, sexual interest is inferred from the length of time participants view different sexual stimuli, such as pictures of adults and children. Researchers have found that ISOCs view images of children longer than non-offending controls (Glasgow, 2009; Harris, Rice, Quinsey, \& Chaplin, 1996; Mokros et al., 2013; Cohen's $d$ s from 0.43 to 1.15) and non-sexual offenders (Babchishin, Nunes, \& Kessous, 2014; Mokros et al., 2013; Cohen's $d$ s from 0.57 to 1.15). For more information, see a recent meta-analytic review by Schmidt, Babchishin, and Lehmann (in press). A limitation of VT was recently highlighted by Imhoff, Schmidt, Weis, Young, and Banse (2012). They found that the outcome data are mainly a function of task-specific effects (e.g., judging $\underline{\text { whether stimuli possess attractive features) rather than stimulus-specific effects (e.g.g }}$ $\underline{\text { schematic processes cued by sexual stimuli). They argued this "has strong implications }}$ regarding the paradigm's robustness and susceptibility to faking" (p. 1396). Based on their $\underline{\text { data, Imhoff et al. (2012) suggest that enhancing automatic effects (by speeding up the task }}$ via the use of a time-constraint) may be more diagnostically beneficial.

Automatic effects are thought to be captured by another commonly used indirect measure; the Implicit Association Test (IAT; Greenwald, McGhee, \& Schwartz, 1998). The $\underline{\text { IAT measures the strength of associations between two concept categories (Child and Adult) }}$ and two attribute categories (Sexy and Not Sexy) using a sorting paradigm. A number of published IAT studies have demonstrated that ISOCs associate children and sex more strongly than adults and sex, relative to non-ISOCs (Babchishin et al., 2014; Babchishin, 
Nunes, Hermann, \& Malcom, 2015; Banse, Schmidt, \& Clarbour, 2010; Brown, Gray, \& Snowden, 2009; Gray, Brown, MacCulloch, Smith, \& Snowden, 2005; Nunes, Firestone, \& Baldwin, 2007). Moreover, most studies have found that child-sex IATs can distinguish ISOCs from non-ISOCs, as shown by Babchishin, Nunes, and Hermann's (2013) in their meta-analysis ( $M$-weighted Cohen's $d=0.63$ ). In addition, child-sex IATs show a positive, albeit moderate, relationship with other measures of sexual interest, such as PPG (Babchishin et al., 2015) and self-report (Babchishin et al., 2014; Schmidt et al., 2014).

A core limitation of the IAT is that it only measures the relative strength of the associations. This is because it involves two target concepts (e.g., adult and child) and two attribute concepts (e.g., sex and not sex). Thus, faster response-latencies when sex-related words/child images are categorized by one key and non-sexual words/adult images are categorized by the other key relative to when the response key assignment is reversed can be interpreted in a number of ways. Participants may: (a) hold stronger child-sex associations; (b) hold stronger adult-not sex associations; (c) lack a child-not sex association; and/or (4) lack an adult-sex association. To address this, variants of the IAT have been developed. This includes the Implicit Relational Assessment Procedure (IRAP; Barnes-Holmes et al., 2006) and the Single-Category IAT (SC-IAT; Karpinski \& Steinman, 2006), both of which have been applied to child-sex associations and were able to differentiate ISOCs from nonoffenders (Dawson, Barnes-Holmes, Gresswell, Hart, \& Gore, 2009; Hempel Buck, Goethals, \& van Marle, 2013, respectively). It should be noted, however, that both studies were designed to assess implicit beliefs about children rather than a sexual interest in children.

\section{The Go/No-Go Association Task}

The first IAT variant to be developed was the Go/No-Go Association Task (GNAT; Nosek \& Banaji, 2001). The GNAT involves separate blocks typically displaying only one target and one attribute concept category (rather than two of each as with the IAT). In each 
block, stimuli are presented for a brief period. Participants must respond - using a single response key - to stimuli representing a target concept and an attribute concept (go trials) but withhold responses to other stimuli or 'distractors' (no-go trials). Response-latencies for all 'go' trials are compared across the separate blocks. If participants show faster responseslatencies to the pairing of a target concept with an attribute concept in one block (e.g., child and sex) relative to the other block (e.g., adult and sex), it is inferred that they hold stronger associations between that particular target and attribute. Thus, the GNAT can measure both the strength of a single association as well as the relative strength of the associations. Moreover, the GNAT can be used to examine associations towards a single category (Nosek \& Banaji, 2001). This is useful for when there is no natural opposite for a particular category. The GNAT has useful in studying numerous phenomena, such as phobias (Teachman, 2007), body dysmorphic disorder (Buhlmann, Teachman, \& Kathmann (2011), and self-harm (Knowles \& Townsend, 2012).

To the authors' knowledge, only one (unpublished) study has used the GNAT to assess child-sex associations in ISOCs (Snowden, Gray, Brown, \& Power, 2007). In this study, Snowden et al. (2007) compared ISOCs $(n=22)$, rapists $(n=19)$, and non-offenders $(n=13)$ on a GNAT (i.e., comparing child + sex, child + non-sex, adult + sex, and adult + non-sex associations). None of the four response-latencies were able to differentiate ISOCs from the two comparison groups. However, when sensitivity was used as the dependent variable (i.e., the ability to discriminate 'go' stimuli from 'no-go' stimuli), ISOCs responded in a manner that suggested a stronger child-sex association compared to rapists $(d=0.73)$. This is interesting as response-latency GNATs are argued to result in greater internal reliability relative to sensitivity-based GNATs because they produce a continuous outcome (i.e., time in milliseconds) rather than a dichotomous outcome (i.e., correct vs. incorrect responses) (Nosek \& Banaji, 2001). 
The reason why response-latencies were unable to differentiate ISOCs in Snowden et al.'s study may be two-fold. First, a short response window was used to categorize stimuli (i.e., $600 \mathrm{~ms}$ and $750 \mathrm{~ms}$ ). Nosek and Banaji (2001) recommend extending the response window when using response-latencies in order to "minimize errors and maximize the range of possible response times" (p. 647). Accordingly, they used a response window of $2000 \mathrm{ms,}$ although other studies have produced valid results using 1400ms windows (Teachman, 2007). Second, in Snowden et al.'s (2007) study, approximately one third of the ISOCs were intrafamilial offenders (i.e., abused a child they were related to). Such individuals typically show lower levels of sexual interest in children compared to those with an extrafamilial offense (i.e., sexual abuse of a child they are unrelated to), as measured phallometrically (Firestone, Bradford, Greenberg, \& Serran, 2000; Quinsey, Chaplin, \& Carrigan, 1979) and psychometrically (Beech, Friendship, Erikson, \& Hanson, 2002). Recognizing this issue, Snowden et al. (2007) recommended using entirely extrafamilial ISOCs in future research using the GNAT.

\section{Current Study}

The present study aimed to investigate whether a response-latency GNAT could be used to assess sexual interest in pre-pubescent children. As mentioned earlier, sexual fantasies typically reflect a sexual interest (Chivers, 2005). Therefore, we used 'sexual $\underline{\text { fantasy' as the attribute label (instead of 'sex', 'sexual', 'sexy'), with 'Adult' and 'Child' as }}$

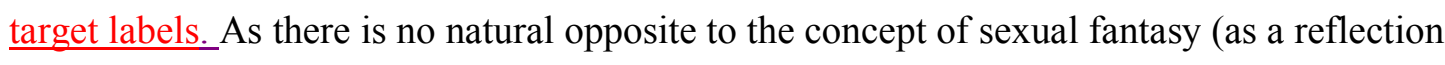
of sexual interest), we used a single-attribute GNAT that consisted of two blocks; one assessing the association between child and sexual fantasy and one assessing the association between adult and sexual fantasy. Furthermore, we: (1) used a response deadline that was double the length of that used by Snowden et al., and (2) focused on exclusively extrafamilial ISOCs. It was hypothesized that extrafamilial ISOCs would show a greater sexual interest in 
children indicated by a stronger association between children and sexual fantasy compared to non-offenders and an ISOC comparison group. It was also hypothesized that stronger associations between children and sexual fantasy would be related to greater self-reported child-related sexual fantasies.

\section{Method}

\section{Participants}

ISOCs were recruited from a secure treatment facility in the state of Wisconsin in the US. Patients were confirmed as being ISOCs if their offense history included a conviction for a sexual offense against a child. Information from the case files was also used to exclude participants who failed to meet the inclusion criteria for the present study. For example, those who had only offended against adults were excluded. Also, since the study focused on sexual interest in pre-pubescent children and involved presenting pictures of pre-pubescent children, we excluded anyone who offended against post-pubescent children (13 years old and over).

Patients with very low cognitive functioning and patients taking antipsychotic medication that affected their motor skills were also excluded.

Due to the limited time-frame for data collection, as many ISOCs were recruited as was possible through opportunity sampling. The final sample consisted of 44 child abusers. From case files, 29 participants were identified as being exclusively extrafamilial $\left(M_{\text {age }}=47\right.$; $S D=10.60)$. The remaining 15 consisted of six exclusively intrafamilial ISOCs and nine mixed offenders (i.e., offenders with both an adult and child victim). Although intrafamilial ISOCs tend to exhibit less sexual interest in children than extrafamilial ISOCs (Firestone et al., 2000; Schmidt et al., 2014), it has been noted that there is a "lack of knowledge on the preferences of 'mixed' offenders" (Michaud \& Proulx, 2009, p. 330). However, it has been argued that individuals who are less preferential in who they victimize harbor a more nonspecific/general sexual deviance (Beauregard, Leclerc, \& Lussier, 2012; Sjostedt, 
Langstrom, Sturidsson, \& Grann, 2004). In support, mixed offenders have been found to have less pre-treatment sexual deviance than child victim-only offenders (Olver, Wong, Nicholaichuk, \& Gordon, 2007) and a similar phallometric response pattern towards stimuli showing consensual adult sex, rape against adult females, and non-violent sexual activity with a child (Michaud \& Proulx, 2009). Based on this literature, it can be argued that mixed offenders will hold a weaker association between children and sexual fantasy relative to the extrafamilial ISOCs. Thus, we decided to collapse the mixed and intrafamilial offenders into a single, composite comparison group labeled 'intra/mixed ISOCs' $\left(M_{\mathrm{age}}=45 ; S D=9.90\right)^{1}$.

The non-offender comparison group, consisting of 26 male students, was recruited from a UK university $\left(M_{\text {age }}=20 ; S D=1.90\right)$. A number of previous studies have used both $\underline{\text { students and non-sexual offenders as comparison groups. In each, the sex-related indirect }}$ measure was able to discriminate sexual offenders from both comparison groups (e.g., Gress, Anderson, \& Laws, 2013; Mihailides et al., 2004; Price, Beech, Mitchell, \& Humphreys, 2013). On this basis, a student/non-offender sample was deemed appropriate as a comparison group for this initial study. As shown in Table 1, on average, participants identified as White $($ extrafamilial $=86 \%$; intra $/$ mixed $=67 \%$; non-offenders $=81 \%$, and were single $($ extrafamilial $=69 \%$; intra $/$ mixed $=73 \%$; non-offenders $=65 \%)$

\section{Insert Table 1 about here}

At the time of the study, the majority of the extrafamilial ISOCs were undergoing treatment $(90 \%)$ with the remaining $10 \%$ of offenders at the pre-treatment stage. Slightly fewer of the intra/mixed group were in treatment (60\%), with the remaining $40 \%$ at the pretreatment stage. Table 1 also shows the offense information for the two offender groups. As

\footnotetext{
${ }^{1}$ Like the exclusive extrafamilial ISOCs, all of the mixed offenders in this study had an extrafamilial child victim. However, only two of the mixed offenders had a male child victim (22\%) relative to the extrafamilial ISOCs $(75 \%)$. Since having a male child victim is stronger indicator of a pedophilic preference (Seto \& Lalumière, 2001), this observation supports the view that mixed offenders (at least in this study) are less sexually interested in children than extrafamilial ISOCs.
} 
shown, extrafamilial ISOCs most often abused both male and female children, whereas intra/mixed ISOCs tended to abuse female children more often, $\chi_{(2)}^{2}=12.60, p<.002$. Table 1 also shows that, while both groups show similar rates of prior sexual offenses, more intra/mixed offenders had committed violent offenses and nonsexual, nonviolent offenses. However, none of these differences were significant. Based on case file information, the two offender groups did not differ on Static-99R scores $(d=0.12)$.

\section{Measures}

Sexual Fantasy-GNAT. A response-latency GNAT was adapted to measure sexual interest in children by assessing the strength of association between sexual fantasy and children (relative to sexual fantasy and adults). The task was programmed using E-Prime (Version 2.0) and administered via a laptop. The GNAT consisted of two blocks; one where participants had to respond to stimuli representing the concept of 'sexual fantasy' and 'child', and one where they responded to stimuli representing the concept of 'sexual fantasy' and 'adult. The concept labels were displayed in the top two corners of the screen and the stimuli were programmed to appear in the center of the screen in a randomized order. Participants were required to respond only to stimuli related to the categories present on-screen (by pressing the spacebar), ignoring those unrelated to these categories. For example, when 'child' and 'sexual fantasy' were displayed on-screen, participants had to respond to images of children and words related to sexual fantasy, and ignore images of adults and words unrelated to sexual fantasy (distractors). Each block consisted of 16 practice trials and 60 critical trials (Teachman, 2007). Stimuli for 'go' trials remained on-screen for 1400ms, while 'no-go' trials remained on screen for 1000ms (Buhlmann et al., 2011; Teachman, 2007). A shorter response window was used for the 'no-go' items because the GNAT requires some pressure to make quick responses (Nosek \& Banaji, 2001). Thus, if all the items were presented for an extended period of time, participants "could intentionally slow down and 
decrease the automaticity of their responses" (Nosek \& Banaji, 2001, p.647). Error feedback was displayed whenever participants made a mistake or did not respond in time.

Stimuli representing target concepts were computer modified images of 15 adults and 15 children. All of the children images were taken from the commercially available Not Real People set (Laws \& Gress, 2004). A set of computer modified adult images developed by Ó Ciardha (2010) were also used. The stimuli for the concept of Sexual Fantasy were words drawn from the literature on (and self-report measures of) sexual fantasy. Finally, 15 distractor words (i.e., words unrelated to sexual fantasy) were chosen in order to form half of the 'no-go' trials. Each distractor word was matched with a Sexual Fantasy word on the first letter, character length, and syllable length (see Appendix for the word list).

Following the recommendation of previous GNAT researchers (Nosek \& Banaji, 2001; Teachman, 2007), trials with overly fast responses $(<300 \mathrm{~ms})$ or very high error rates (more than $40 \%$ on each block or more than $30 \%$ overall) were removed. However, no participants had error rates greater than this recommendation. Timed-out responses (i.e., 'no response') for 'go' trials were recorded as zero. A conservative procedure was employed to account for these timed-out errors, which involved changing the zeros to the duration deadline for critical stimuli (1400ms), as recommended by Nosek (personal communication, June 6, 2012). Responses for distractor trials were removed as they are considered noise (Nosek \& Banaji, 2001). We also screened for outliers using the 'outlier labeling rule' proposed by Hoaglin and Iglewicz (1987). One outlier was found in the Child block for the non-offender group and removed from the final sample, resulting in 25 non-offenders being used in the final sample.

Split-half reliabilities - using an odd-even split - were used to assess the internal consistency of the Sexual Fantasy-GNAT (Williams \& Kaufmann, 2012). First, we divided the task into odd trials and even trials for each block of the GNAT, as well as for the overall 
task. Second, Spearman-Brown corrected correlations were run between the odd and even trials for each block and for the overall task. The resulting reliabilities were as follows: Sexual Fantasy+Child, $r=0.93$; Sexual Fantasy+Adult, $r=0$. 85; overall GNAT, $r=0.94$. Thus, the Sexual Fantasy-GNAT had a very good internal consistency, particularly for a reaction-time measure (Nosek, Greenwald, \& Banaji, 2007).

Control-GNAT. In order to corroborate that the GNAT had the capability to capture child-related associations in general, a control GNAT was developed. This GNAT was designed to assess and compare Child-Toy and Adult-Toy associations. It was hypothesized that all participants would associate children and toys more strongly than adults and toys. The 15 stimulus words were common toys (e.g., yoyo). There were also 15 different distractor words, matched to the Toy words on starting letter, syllable length, and character length (see Appendix). Children and adult-related stimuli were images taken from the NRP set and Ó Ciardha's (2010) set, different to those used in the Sexual Fantasy-GNAT. The control GNAT was subjected to the same scoring procedure as described above.

Wilson Sexual Fantasy Questionnaire (WSFQ; Wilson, 1978). The WSFQ is a 40item questionnaire that uses a 6-point scale - ranging from 0 (Never) to 5 (Regularly) - to measure how frequently a respondent uses 40 specific fantasies. These fantasies are grouped into four themes/subscales each comprised of 10 items; namely, Exploratory (i.e.. Participating in an orgy), Intimate (i.e., Kissing passionately), Impersonal (i.e., Intercourse with an anonymous stranger), and Sadomasochistic (i.e., Hurting a partner). In a sample of ISOCs, Baumgartner, Scalora, and Huss (2002) found high internal consistencies for each subscale ( $\alpha$ 's ranging from .83 to .92). Moreover, Baumgartner et al. (2002) argued that there are two child-related items on the WSFQ ("Having sex with someone much younger than yourself" and "Seducing an innocent"), both of which were rated significantly higher by ISOCs relative to non-sex offenders. 
Thoughts and Fantasies Questionnaire (Thornton, unpublished). This is an openended questionnaire that assesses offenders' use of deviant sexual fantasies during their time in treatment. The measure focuses on six specific fantasies; abduction, force, children under 13 years, children between 13 and 17 years old, sexual sadism, and past victims. If the respondent admits to using a fantasy, they are asked to answer further open-ended questions, such as what was the most often the fantasy was used in a month, when it was last used, and how long it lasted for. It also asks the respondent to write out the fantasy in detail. Thus, this measure is unique as it is able to establish whether respondents use elaborate imagery, as opposed to fleeting sexual thoughts. For this study, only sexual fantasies involving prepubescent children were of interest. Since this questionnaire does not provide continuous data, a dichotomous variable ('deviant fantasizer' scored as Yes/No) was created. An individual was deemed a deviant fantasizer if sexual fantasies of a pre-pubescent child were: used more than once in a month; lasted longer than a few seconds; and were clearly elaborate (i.e., involved a clear script/scenario).

\section{Procedure}

ISOCs were informed that a study was taking place examining responses to pictures of people and words related to sex. They were informed that participation was voluntarily and to indicate their interest using a sign-up sheet that was left on the wing. After the sign-up $\underline{\text { sheets were collected, eligible participants were scheduled to come to a quiet room where the }}$ study took place. The student sample was also recruited through opportunity sampling. Here, participants signed-up (via the university's research participation scheme) to take part in a $\underline{\text { study examining responses to pictures of people and words related to sex. }}$ After entering the room/lab, each participant first read a brief form outlining the $\underline{\text { nature and requirements of the study. After obtaining informed consent, demographic data }}$ were collected (e.g., age, relationship status, ethnicity). Following this, three different 
response-latency indirect measures (two GNATs, an Implicit Association Test (IAT), and two Sorting Paired Features (SPF) tasks) were administered in a randomized order $^{2}$, along with the two self-report measures of sexual fantasy. The control GNAT was always administered before the Sexual Fantasy-GNAT. This allowed participants to become familiar with the general GNAT procedure before completing the critical Sexual Fantasy-GNAT. For each GNAT, participants read the on-screen instructions before completing a short practice phase. Once ready, they went on to complete the critical phase. Half of the participants completed the Sexual Fantasy + Child block first, while the other half completed the Sexual Fantasy + Adult block first. Note, the indirect and self-report measures were completed in a counterbalanced order between participants.

\section{Results}

Given the small samples sizes, emphasis is placed upon the effect sizes when interpreting the results of this study, rather than (or in addition to) significance testing. Also, focusing on effect sizes allows for the magnitude of the group differences or relationships to be highlighted. Thus, for correlations, an $r$ of .10 is considered small; .30 is considered moderate; and .50 is considered large (Cohen, 1992). According to Ferguson (2009), these $\underline{\text { same guidelines can be applied to Spearman's Rho coefficients (p. 533). For point-biserial }}$ correlations, an $r_{p b}$ of .10 is considered small; .24 is considered moderate; and .37 is considered large (Rice \& Harris, 2005). For Cohen's $d, 0.20$ is considered small, 0.50 is considered moderate, and 0.80 is considered large (Cohen, 1992). Descriptive statistics are presented in Table 1.

\section{Group differences}

\footnotetext{
${ }^{2}$ The GNAT was explicitly designed to assess sexual interest in children, while the SPF/IAT were aimed at untangling the 'child/adult'-'sex/not sex' associations thought to underpin distorted cognition. Therefore, only the results of the GNATs are reported in the present study.
} 
Sexual Fantasy GNAT. A 2 (Block: Sexual Fantasy+Child vs. Sexual Fantasy+Adult) x 3 (Group: Extrafamilial vs. Intra/mixed vs. Non-offender) mixed ANOVA was performed on the raw response-latencies, with Block as the within-subjects factor and Group as the between-subjects factor. The main effect for Block was marginally significant, $\left(F(1,66)=3.73, p=.058, \eta^{2}=.052\right)$, reflecting faster responses on the Adult block $(M=$ $624 \mathrm{~ms})$ compared to the Child block $(M=641 \mathrm{~ms})$. No main effect was found for Group, $\left(F(2,66)=.264, p=.77, \eta^{2}=.006\right.$. However, a significant Block x Group disordinal interaction was found $\left(F(2,66)=5.71, p=.005, p=.003, \eta^{2}=.149\right)$, indicating differential responding across the blocks by group. Follow-up analyses (with Bonferroni correction) revealed that non-offenders' responses were faster in the Adult block $(M=608.31 \mathrm{~ms}, S E=$ 17.04) than the Child block $(M=645.12 \mathrm{~ms}, S E=18.01)(p=.01, d=.43)$. The intra $/ \mathrm{mixed}$ group also showed faster response on the Adult block $(M=626.89 \mathrm{~ms}, S E=22.00)$ compared to the Child block $(M=661.21 \mathrm{~ms}, S E=23.25)(p=.06, d=0.36)$. Conversely, the extrafamilial ISOCs exhibited (non-significant but non-negligible) faster responding on the Child block $(M=616.71 \mathrm{~ms}, S E=18.63)$ relative to the Adult block $(M=637.74 \mathrm{~ms}, S E=$ 16.72) $(p=.11, d=0.22)$.

The pattern of group differences within each block were as predicted (see Table 2). For example, on the Child block, the extrafamilial ISOCs showed faster responses than both the non-offenders $(d=0.43)$ and the intra/mixed ISOCs $(d=0.44)$. However, the nonoffenders and intra/mixed ISOCs did not differ $(d=0.01)$. Within the Adult block, a small effect was found when comparing the extrafamilial ISOCs to the non-offenders $(d=0.21)$, while little difference was observed between the extrafamilial and intra/mixed ISOCs $(d=$ 0.12). Finally, the non-offenders and intra/mixed ISOCs did not differ $(d=0.09)$.

Insert Table 2 about here 
To explore the interaction further, the three groups were compared on a 'mean difference score'. This also allowed us to examine whether a relative score (akin to a deviance index) could discriminate groups. This index was computed by subtracting the mean response-latencies for the Child block from the mean response-latencies for the Adult block. Positive values reflected faster responding during the Child block relative to the Adult block. Negative values represented faster responding during the Adult block. As expected, the results of a one-way, independent measures ANOVA mirrored the significant interaction found from the previous two-way $\operatorname{ANOVA}\left(F(1,66)=5.71, p=.005, \eta^{2}=.157\right)$. As shown in Table 2, post-hoc analyses (with Bonferroni correction) revealed that extrafamilial ISOCs had a greater mean difference score than the non-offenders $(p=.009, d=-0.83)$ and the intra/mixed $\operatorname{ISOCs}^{3}(p=.043, d=-0.89)$. The non-offenders and the intra/mixed ISOCs differed to a far lesser extent $(p=.92, d=-0.33)$.

Control GNAT. On the control task, a two-way ANOVA on the response-latencies revealed a main effect for Block, $F(1,66)=9.70 ; p=.003, \eta^{2}=.086$, reflecting faster responding on the Toy-Child block $(M=618.83 \mathrm{~ms})$ than the Adult-Toy block $(M=$ $649.69 \mathrm{~ms}$ ) across all three groups. This supports the view that all participants would associate toys with children more so than adults. There was no main effect for Group nor was there an interaction between Block and Group, supporting the prediction that the groups would not differ in their association between children and toys. This provides corroborating evidence that the GNAT can be used to assess child-related associations. However, it should be noted that, when observing the effect sizes, extrafamilial ISOCs showed faster responses during the Toy-Child block relative to the intra/mixed ISOCs.

\section{Convergent validity}

\footnotetext{
${ }^{3}$ The mean difference scores for the intrafamilial group $(M=-34.07)$ and the mixed group $(M=-34.47)$ were near identical $(d=0.01)$. Moreover, exploratory analyses indicated that the mean difference scores for the extrafamilial group differed from both the intrafamilial $(d=0.87)$ and mixed group $(d=0.84)$. These results justified our collapsing of the two subgroups into one composite comparison group.
} 
Spearman's Rho correlation analyses revealed that sexual fantasies about children (as measured by the Thoughts and Fantasies Questionnaire) were strongly related to the two child-related items of the WSFQ (see Table 3). However, none of the child-related sexual fantasy measures correlated with the response-latencies for each block of the Sexual Fantasy GNAT. However, faster responses on the Child block showed a small relationship with the Intimate subscale of the WSFQ $\left(r_{s}=-.21\right)$. Also, faster responses on the Adult block showed a significant, small relationship with the Impersonal subscale $\left(r_{s}-.26\right)$, as well as a small (nonsignificant) relationship with the Sadomasochistic subscale $\left(r_{s}=.20\right)$. More in line with our hypothesis, the mean difference score showed a moderate positive relationship with selfreported sexual fantasies about children, as measured by the Thoughts and Fantasies Questionnaire $\left(r_{s}=.31\right)$. Also, the mean difference score showed a small, negative correlation with the Sadomasochistic $\left(r_{s}=-.26\right)$ and Impersonal subscale of the WSFQ $\left(r_{s}=-.21\right)$. This suggests that faster responding on Adult block (relative to the Child block) was associated with these two sexual fantasy themes.

\section{Insert Table 3 about here}

\section{Discriminative validity}

Previous studies have used the area under the curve (AUC) of a receiver operating characteristic (ROC) to examine whether child-sex IAT scores can effectively discriminate ISOCs from controls (Babchishin et al., 2013; Banse et al., 2010; Gray et al., 2005). AUC values range from zero to one. According to Rice and Harris (2005), AUCs of .56, .64, and .71 correspond to small (.20), medium (.50), and large (.80) Cohen's $d$ values of effect size (Cohen, 1992). Intra/mixed ISOCs were indistinguishable from non-offenders (AUC $=.51, p$ $=.94)$. However, extrafamilial ISOCs were discriminated from non-offenders (AUC $=.71, p$ $=.007)$. This level of discrimination was greater than when ISOCs as a homogenous group were used $(\mathrm{AUC}=.64)$. In addition, extrafamilial ISOCs were discriminated from the 
intra/mixed ISOCs (AUC $=.73, p=.01)$, as well as the intra/mixed and non-offenders combined $(n=40)($ AUC $=.72, p<.002)$. Following the hypothesis that extrafamilial ISOCs have a stronger sexual interest in children, these findings suggest the Sexual Fantasy-GNAT is able to discriminate abusers with a greater sexual interest in children. This was further corroborated by examining how well the GNAT discriminated ISOCs who were 'deviant fantasizers' (based on responses from the Thoughts and Fantasies Questionnaire) from nonfantasizers. There were 29 deviant fantasizers - of which 21 were extrafamilial and eight were intra/mixed - and 15 non-fantasizers. The GNAT, again, showed good discriminative ability $(\mathrm{AUC}=.70, p=.04)$

\section{Discussion}

The main aim of the present study was to investigate whether the GNAT could be used as an indirect measure of sexual interest in children. It was hypothesized that extrafamilial such individuals would demonstrate faster response-latencies when responding to child and sexual fantasy related stimuli (compared to adult and sexual fantasy stimuli) than would a composite group of intrafamilial and mixed offenders (who had offended against both children and adults), and a group of non-offenders. Our results provided support for this hypothesis. In line with previous IAT research, using response-latency indices (i.e., the mean difference between the child block and adult block), the extrafamilial group responded in a manner indicative of a sexual preference for children. That is, compared to both comparison groups, the extrafamilial group demonstrated faster response-latencies on the child block relative to the adult block. These results suggest that extrafamilial ISOCs have a stronger associative bias for children and sexual fantasy (relative to adults and sexual fantasy), compared to non-offenders and intra/mixed ISOCs.

A unique feature of the GNAT that distinguishes it from the original IAT is its capability to assess absolute associations (e.g., between children and sexual fantasy only). As 
expected, we found that both comparison groups exhibited faster responses on the Adult block, while the extrafamilial group showed faster responding on the Child block. Further, an examination of the effect sizes indicated that the extrafamilial ISOCs responded faster than both comparison groups on the Child block, while the two comparison groups did not differ from each other. These results are also in line with our hypotheses. The lack of significance in the group differences is likely a result of low power and, thus, highlights the need for follow-up research with larger samples. However, it should be noted that the mean difference score was able to differentiate extrafamilial ISOCs from both comparison groups to a far stronger degree than the absolute child-sexual fantasy association. This could suggest that relative scores (akin to a deviance index) may be a better outcome variable to use if one wishes to maximize group discrimination. This is similar to what is recommended for PPG data (Harris, Rice, Quinsey, Chaplin, \& Earls, 1992).

Similar to Teachman (2007), we wanted to confirm that the GNAT is capable of assessing child-related associations. Thus, a control GNAT assessing Child-Toy (versus Adult-Toy) associations was constructed. As predicted, all participants showed faster responding on the Child-Toy block, corroborating the proposition that the GNAT is a viable tool for detecting child-related associations. Although the groups did not significantly differ on each block, the effect sizes did suggest that extrafamilial ISOCs were faster than the intra/mixed group on the Child-Toy block, perhaps reflecting a general bias towards children.

In addition to known-groups validation, convergent validity was examined. Neither of the absolute GNAT scores or the mean difference score showed a relationship with the two child-related WSFQ items. However, the mean differences score was positively correlated with child-related sexual fantasies as measured by the Thoughts and Fantasies Questionnaire. The lack of a relationship between the Sexual Fantasy-GNAT and the two WSFQ items may be due to a lack of sensitivity due to the ambiguity these items (O'Donohue, Letourneau, \& 
Dowling, 1997). Although these two items correlated strongly with the child-related item of the Thoughts and Fantasies questionnaire (see Table 3) and are used more frequently by ISOCs than non-offenders (Baumgartner et al., 2002), they do not explicitly ask about sexual activity with children. Rather, they ask about an 'innocent' and 'someone much younger than yourself'. An innocent could be interpreted as someone who is a virgin, which is not exclusively equivalent to a child. Moreover, the ISOCs' mean age ranged from 45-47 years old. Thus, 'someone much younger' could be interpreted as a young adult such as someone in their twenties; not necessarily a child. Future research should test whether the Sexual Fantasy-GNAT (or a related variant) correlates with other indices of sexual interest, such as PPG scores and sexual interest items from validated risk measures. In sum, these results provide partial support for the convergent validity of the Sexual Fantasy-GNAT. However, keep in mind that: (1) the size of the relationship between the GNAT mean difference and Thoughts and Fantasies Questionnaire was only moderate $\left(r_{s}=.31\right)$, and (2) the WSFQ items may not have provided a good test of convergent validity given that the two items do not explicitly refer to children.

Responses on the Child block did show a small relationship with the Intimate subscale of the WSFQ. This suggests that a stronger associative sexual bias towards children is related to more frequent use of intimate sexual fantasies. It could be argued that, for ISOCs, these intimate fantasies involve children. However, this cannot be determined as the WSFQ items asked about intimate behaviour, not the type of person that the participant envisions engaging in the intimate behavior with. This is a something worth following up in future research. Faster responses on the Adult block were significantly associated with Impersonal sexual fantasies. As noted by Seifert, Boulas, Huss, and Scalora (2015) “experiencing repeated sexual fantasies among sexual offenders commonly leads to hypersexuality...Furthermore, these persons experiencing hypersexuality often have less relational sexual fantasies" (p.2). 
Thus, it could be argued that faster responses on the Adult block are indicative of greater hypersexuality as - in accordance with Seifert et al. (2015) - it was related to more frequent use of less relational (i.e., impersonal) sexual fantasies. Although this is speculative, investigating whether adult-sex associations are associated with greater hypersexuality (mediated by Impersonal sexual fantasies) would be an interesting avenue for future research.

Finally, the discriminative validity of the GNAT was examined. When adopting the same approach as previous studies using indirect measures (i.e., the ability to distinguish ISOCs from non-offenders), a medium effect was observed $(\mathrm{AUC}=.64)$. However, given that the intra/mixed group of offenders showed a very similar response pattern to the nonoffenders on the GNAT, this approach would likely increase the number of false negatives. That is, the intra/mixed ISOCs would be incorrectly identified as not being an offender. Indeed, when examining the GNAT's ability to discriminate extrafamilial abusers from intra/mixed and non-offenders, a larger effect was found $(\mathrm{AUC}=.72)$. While these findings need to be corroborated in future research, they highlight two important points. First, testing whether responses on an indirect measure of sexual interest can distinguish who is and is not an offender does not account for the heterogeneity among ISOCs. In other words, this approach essentially treats all ISOCs as having a sexual preference for children, which is not the case (Johnson, 2006; Schmidt, Mokros, \& Banse, 2013). Furthermore, not everyone with a sexual interest in children is an offender. Recent research suggests that between three and nine percent of the general population have a sexual interest in children (Dombert et al., 2015; Wurtele, Simons, \& Moreno, 2014). Thus, had any of the non-offenders in the present study (or in subsequent studies) held a sexual interest in children, they would have been misidentified as being an offender.

Second, using an indirect measure to differentiate ISOCs from those who have not sexually offended does not actually correspond with the intended use of the task. That is, 
indirect measures (such as the one used in this study) are adapted to measure deviant sexual interest. Thus, attempting to detect offender status is not the most effective way to assess the validity of an indirect measure of deviant sexual interest (Babchishin et al., 2015). Instead, the aim should be to differentiate participants on a feature that more closely relates to a sexual interest in children, such as risk category or victim type (as in the present study). Another approach is to group participants based on their response on another sexual interest measure (e.g., PPG, self-report). This approach was attempted in the present study. Using their responses on the child-related item of a sexual fantasy measure, ISOCs were categorized as either being 'fantasizers' (eight of whom were intra/mixed offenders) or 'non-fantasizers'. The GNAT was able to effectively discriminate fantasizers $(\mathrm{AUC}=.70)$.

\section{Limitations}

There are a few limitations in this study that should be noted. First, many of the ISOCs were in treatment. It is possible that, due to regularly discussing their sexual interests in treatment, some offenders may have formed stronger associations between children and sexual fantasy. However, there is no reason to think that extrafamilial ISOCs talk about the topic of sexual interest and fantasies in treatment any more than intrafamilial and mixed ISOCs do. Second, although the effect sizes for the group differences were promising, the sample sizes were small. Thus, to corroborate these preliminary findings, a replication study using larger samples is warranted. Third, due to low numbers, a comparison group comprised of intrafamilial and mixed ISOCs was used. The existing literature and_near-identical GNAT scores produced by these two subgroups justified this approach. However, a comparison group comprised solely of intrafamilial ISOCs should be recruited and used in follow-up studies.

Fourth, the non-offender group was comprised of students. Previous studies tend to use non-sex offenders as a comparison group as they can be better matched to the sex 
offender sample. Thus, this approach should be adopted in future studies using the GNAT. It should be noted that if there were any age-related differences (e.g., differences in processing speed) between the ISOCs and students, we would expect to see a greater difference in GNAT responses between the intra/mixed group and students. However, this was not observed. Fifth, the coding of the ISOCs as 'deviant fantasizers' was only done by the first author. In hindsight, it would have been beneficial to have had more researchers involved in the coding procedure, thus, allowing for inter-rater reliability to be calculated. Finally, while not necessarily a limitation, 'sexual fantasy' was used as the single-target attribute on the GNAT. This is because sexual fantasies tend to reflect sexual interests. Thus, the findings do not indicate that the Sexual Fantasy-GNAT provides an indirect assessment of participants' sexual fantasies; rather, it is seen as providing a proxy for the presence of a sexual interest. The issue here, however, is that is not known whether another attribute label would have performed better. Therefore, future researchers are encouraged to use alternative labels to see if the GNAT performs equally as well (or better) than the one in this study.

\section{Conclusion}

Despite these limitations, the results of this study mirror previous indirect measure research and, thus, provide the first indication that a latency-based GNAT can be used to assess sexual interest in children. They also highlight the need to consider offender heterogeneity when using indirect measures. This study has demonstrated the GNAT's value as a research tool, as it offers features that are not available to the traditional IAT. These include being able to assess associations towards a single concept and allowing for the measurement of absolute associations. In the present study, the latter was shown to be useful for examining within-group differences between the each absolute association and, to some degree, the differences between the groups on each association. However, from our results, it would appear that the mean difference between the single associations (similar to a deviance 
index) is a better outcome variable for discriminating groups. In all, our preliminary findings suggest that the GNAT holds promise as a tool that forensic professionals can use as an adjunct to other sexual interest measures. 


\section{References}

Allan, M., Grace, R. C., Rutherford, B., \& Hudson, S. M. (2007). Psychometric assessment of dynamic risk factors for child molesters. Sexual Abuse: A Journal of Research and Treatment, 19, 347-367. doi: 10.1177/107906320701900402

Babchishin, K. M., Nunes, K. L., \& Hermann, C. A. (2013). The validity of Implicit Association Test (IAT) measures of sexual attraction to children: A meta-analysis. Archives of Sexual Behavior, 42, 487-499. doi:10.1007/s10508-012-0022-8.

Babchishin, K. M., Nunes, K. L., \& Kessous, N. (2014). A Multimodal Examination of Sexual Interest in Children A Comparison of Sex Offenders and Non-sex Offenders. Sexual Abuse: A Journal of Research and Treatment, 26, 343-374. doi:10.1177/1079063213492343

Babchishin, K. M., Nunes, K. L., Hermann, C. A., \& Malcom, J. R. (2015). Implicit sexual interest in children: Does separating gender influence discrimination when using the Implicit Association Test? Journal of Sexual Aggression, 21, 194-208. doi:10.1080/13552600.2013.836575

Banse, R., Schmidt, A. F., \& Clarbour, J. (2010). Indirect measures of sexual interest in child sex offenders: A multimethod approach. Criminal Justice and Behavior, 37, 319-335. doi:10.1177/0093854809357598.

Barnes-Holmes, D., Barnes-Holmes, Y., Power, P., Hayden, E., Milne, R., \& Stewart, I. (2006). Do you really know what you believe? Developing the Implicit Relational Assessment Procedure (IRAP) as a direct measure of implicit beliefs. The Irish Psychologist, 32, 169-177.

Bartels, R. M., \& Gannon, T. A. (2011). Understanding the sexual fantasies of sex offenders and their correlates. Aggression and Violent Behavior, 16, 551-561. doi:10.1016/j.avb.2011.08.002 
Baumgartner, J. V., Scalora, M. J., \& Huss, M. T. (2002). Assessment of the Wilson Sex Fantasy Questionnaire among child molesters and nonsexual forensic offenders. Sexual Abuse: A Journal of Research and Treatment, 14, 19-30. doi:10.1023/A:1013025410090

Beauregard, E., Leclerc, B., \& Lussier, P. (2012). Decision-making in the crime-commission process: Comparing rapists, child molesters, and victim-crossover sex offenders. Criminal Justice and Behavior, 39, 1275-1295. doi:10.1177/0093854812453120.

Beech, A., Friendship, C., Erikson, M., \& Hanson, R. K. (2002). The relationship between static and dynamic risk factors and reconviction in a sample of UK child abusers. Sexual Abuse: A Journal of Research and Treatment, 14, 155-167. doi:10.1023/A:1014672231744.

Beggs, S. M., \& Grace, R. C. (2010). Assessment of dynamic risk factors: An independent validation study of the violence risk scale: Sexual offender version. Sexual Abuse: A Journal of Research and Treatment, 22, 234-251. doi: 10.1177/1079063210369014

Beggs, S., \& Grace, R. C. (2011). Treatment gain for sexual offenders against children predicts reduced recidivism: A comparative validity. Journal of Consulting and Clinical Psychology, 79, 182-192. doi.org/10.1037/a0022900.

Brown, A. S., Gray, N. S., \& Snowden, R. J. (2009). Implicit measurement of sexual associations in child sex abusers role of victim type and denial. Sexual Abuse: A Journal of Research and Treatment, 21, 166-180. doi:10.1177/1079063209332234

Buhlmann, U., Teachman, B. A., \& Kathmann, N. (2011). Evaluating implicit attractiveness beliefs in body dysmorphic disorder using the Go/No-go Association Task. Journal of Behavior Therapy and Experimental Psychiatry, 42, 192-197.

doi:10.1016/j.jbtep.2010.10.003 
Chivers, M. L. (2005). A brief review and discussion of sex differences in the specificity of sexual arousal. Sexual and Relationship Therapy, 20, 377-390. doi:10.1080/14681990500238802.

Cohen, J. (1992). A power primer. Psychological Bulletin, 112, 155-159. doi:10.1037/0033-2909.112.1.155

Dawson, D. L., Barnes-Holmes, D., Gresswell, D. M., Hart, A. J., \& Gore, N. J. (2009). Assessing the implicit beliefs of sexual offenders using the implicit relational assessment procedure a first Study. Sexual Abuse: A Journal of Research and Treatment, 21, 57-75. doi:10.1177/1079063208326928

Dombert, B., Schmidt, A. F., Banse, R., Briken, P., Hoyer, J., Neutze, J., \& Osterheider, M. (2015). How common is males' self-reported sexual interest in prepubescent children? Journal of Sex Research. Online version. doi:10.1080/00224499.2015.1020108

Ferguson, C. J. (2009). An effect size primer: A guide for clinicians and researchers. Professional Psychology: Research and Practice, 40, 532-538. doi:10.1037/a0015808

Firestone, P., Bradford, J. M., Greenberg, D. M., \& Serran, G. A. (2000). The relationship of deviant sexual arousal and psychopathy in incest offenders, extrafamilial child molesters, and rapists. Journal of the American Academy of Psychiatry and the Law, 28, 303-308.

Gannon, T., Terriere, R., \& Leader, T. (2012). Ward and Siegert's Pathways Model of child sexual offending: A cluster analysis evaluation. Psychology, Crime \& Law, 18, 129153. doi:10.1080/10683160903535917

Gray, N. S., Brown, A. S., MacCulloch, M. J., Smith, J., \& Snowden, R. J. (2005). An implicit test of the associations between children and sex in pedophiles. Journal of Abnormal Psychology, 114, 304-308. doi:10.1037/0021-843X.114.2.304 
Greenwald, A. G., McGhee, D. E., \& Schwartz, J. L. K. (1998). Measuring individual differences in implicit cognition: The Implicit Association Test. Journal of Personality and Social Psychology, 74, 1464-1480. doi:10.1037/0022-3514.74.6.1464

Gress, C. L. Z., Anderson, J. O., \& Laws, D. R. (2013). Delays in attentional processing when viewing sexual imagery: The development and comparison of two measures. Legal and Criminological Psychology, 18, 66-82. doi:10.1111/j.20448333.2011.02032.x

Hanson, R. K., \& Morton-Bourgon, K. E. (2005). The characteristics of persistent sexual offenders: a meta-analysis of recidivism studies. Journal of Consulting and Clinical Psychology, 73, 1154-1163. doi:10.1037/0022-006X.73.6.1154

Harris, G. T., Rice, M. E., Quinsey, V. L., \& Chaplin, T. C. (1996). Viewing time as a measure of sexual interest among child molesters and normal heterosexual men. Behaviour Research and Therapy, 34, 389-394. doi:10.1016/0005-7967(95)00070-4.

Hempel, I. S., Buck, N. M. L., Goethals, K. R., \& Van Marle, H. J. C. (2013). Unraveling sexual associations in contact and noncontact child sex offenders using the single category-implicit association test. Sexual Abuse: A Journal of Research and Treatment, 25, 444-460. doi:10.1177/1079063212464660

Hudson, S. M., Wales, D. S., Bakker, L., \& Ward, T. (2002). Dynamic risk factors: The Kia Marama evaluation. Sexual Abuse: A Journal of Research and Treatment, 14, 103119. doi:10.1023/A:1014616113997

Imhoff, R., Schmidt, A. F., Weis, S., Young, A. W., \& Banse, R. (2012). Vicarious Viewing Time: Prolonged response latencies for sexually attractive targets as a function of task- or stimulus-specific processing. Archives of Sexual Behavior, 41, 1389-1401. doi: 10.1007/s 10508-011-9879-1

Johnson, S.A. (2007). Physical abusers and sexual offenders: Forensic and clinical 
strategies. Boca Rotan, Florida: CRC/Taylor \& Francis.

Kalmus, E., \& Beech, A. R. (2005). Forensic assessment of sexual interest: A review. Aggression and Violent Behavior, 10, 193-217. doi:10.1016/j.avb.2003.12.002

Karpinski, A., \& Steinman, R. B. (2006). The single category implicit association test as a measure of implicit social cognition. Journal of Personality and Social Psychology, 91, 16-32. doi:10.1037/0022-3514.91.1.16

Knowles, S. E., \& Townsend, E. (2012). Implicit and explicit attitudes toward self harm: Support for a functional model. Journal of Behavior Therapy and Experimental Psychiatry, 43, 730-736. doi:10.1016/j.jbtep.2011.10.007

Laws, D. R., \& Gress, C. L. Z. (2004). Seeing things differently: The viewing time alternative to penile plethysmography. Legal and Criminological Psychology, 9, 183-196. doi: $10.1348 / 1355325041719338$

Michaud, P., \& Proulx, J. (2009). Penile-response profiles of sexual aggressors during phallometric testing. Sexual Abuse: A Journal of Research and Treatment, 21, 308-334. doi: 10.1177/1079063209342073.

Mihailides, S., Devilly, G. J., \& Ward, T. (2004). Implicit cognitive distortions and sexual offending. Sexual Abuse: A Journal of Research and Treatment, 16, 333-350. doi:10.1023/B:SEBU.0000043327.10168.5b

Mokros, A., Gebhard, M., Heinz, V., Marschall, R. W., Nitschke, J., Glasgow, D. V., Gress, C. L., \& Laws, D. R. (2013). Computerized assessment of pedophilic sexual interest through self-report and viewing time: reliability, validity, and classification accuracy of the affinity program. Sexual Abuse: A Journal of Research and Treatment, 25, 230258. doi: $10.1177 / 1079063212454550$.

Nosek, B. A., \& Banaji, M. R. (2001). The Go/No-go association task. Social Cognition, 19, 625-666. doi:10.1521/soco.19.6.625.20886 
Nosek, B. A., Greenwald, A. G., \& Banaji, M. R. (2007). The Implicit Association Test at age seven: A methodological and conceptual review. In J. A. Bargh (Ed.), Social Psychology and the unconscious: The automaticity of higher mental processes (pp. 265-292). New York: Psychology Press.

Nunes, K. L., Firestone, P., \& Baldwin, M. W. (2007). Indirect assessment of cognitions of child sexual abusers with the Implicit Association Test. Criminal Justice and Behavior, 34, 454-475. doi:10.1177/0093854806291703

Ó Ciardha, C. (2010). The use of implicit cognitive measures in the assessment of sexual offenders (Doctoral thesis). University of Dublin, Trinity College, Dublin Ireland.

O’Donohue, W., Letourneau, E. J., \& Dowling, H. (1997). Development and preliminary validation of a paraphilic sexual fantasy questionnaire. Sexual Abuse: A Journal of Research and Treatment, 9, 167-178. doi:10.1007/BF02675062

Olver, M. E., Wong, S. C., Nicholaichuk, T., \& Gordon, A. (2007). The validity and reliability of the Violence Risk Scale-Sexual Offender version: Assessing sex offender risk and evaluating therapeutic change. Psychological Assessment, 19, 318329. doi.org/10.1037/1040-3590.19.3.318

Price, S. A., Beech, A. R., Mitchell, I., \& Humphreys, G. W. (2013a). Measuring deviant sexual interest using the emotional Stroop task. Criminal Justice and Behavior, 40, 970-987 doi: 10.1177/0093854813476264.

Quinsey, V. L., Chaplin, T. C., \& Carrigan, W. F. (1979). Sexual preferences among incestuous and nonincestuous child molesters. Behavior Therapy, 10, 562-565. doi:10.1016/S0005-7894(79)80057-X

Rice, M. E., \& Harris, G. T. (2005). Comparing effect sizes in follow-up studies: ROC Area, Cohen's i, and r. Law and Human Behavior, 29, 615-620. doi:10.1007/s10979-005-6832-7 
Rullo, J., Strassberg, D. S., \& Israel, E. (2010). Category-specificity in sexual interest in gay men and lesbians. Archives of Sexual Behavior, 39, 874-879. doi: 10.1007/s10508-009-9497-3

Seifert, K., Boulas, J., Huss, M. T., \& Scalora, M. J. (2015). Response bias on self-report measures of sexual fantasies among sexual offenders. International Journal of Offender Therapy and Comparative Criminology. doi: 10.1177/0306624X15593748.

Seto, M. C., \& Lalumière, M. L. (2001). A brief screening scale to identify pedophilic interests among child molesters. Sexual Abuse: A Journal of Research and Treatment, 13, 15-25. doi:10.1177/107906320101300103.

Schmidt, A. F., Babchishin, K. M., \& Lehmann, R. J. (in press). A meta-analysis of viewing time measures of sexual interest in children. Archives of Sexual Behavior. Retrieved from: https://www.researchgate.net/publication/304526820_A_MetaAnalysis_of_Viewing_Time_Measures_of_Sexual_Interest_in_Children

Schmidt, A. F., Mokros, A., \& Banse, R. (2013). Is pedophilic sexual preference continuous? A taxometric analysis based on direct and indirect measures. Psychological Assessment, 25, 1146-1153. doi:10.1037/a0033326

Schmidt, A. F., Gykiere, K., Vanhoeck, K., Mann, R. E., \& Banse, R. (2014). Direct and indirect measures of sexual maturity preferences differentiate subtypes of child sexual abusers. Sexual Abuse: A Journal of Research and Treatment, 26, 107-128. doi:10.1177/1079063213480817

Sjostedt, G., Langstrom, N., Sturidsson, K., \& Grann, M. (2004). Stability of modus operandi in sexual offending. Criminal Justice and Behavior, 31, 609-623. doi:10.1177/009385480426 7094 
Snowden, R. J., Craig, R. L., \& Gray, N. S. (2011). Indirect behavioral measures of cognition among sexual offenders. Journal of Sex Research, 2, 192-217. doi:10.1080/00224499.2011.557750

Snowden, R. J., Gray, N. S., Brown, A. S., \& Power, S. (2007). Measuring implicit cognitions in sexual offenders using the Go/No-Go Task. Unpublished dissertation.

Stinson, J. D., \& Becker, J. V. (2008). Assessing sexual deviance: A comparison of physiological, historical, and self-report measures. Journal of Psychiatric Practice, 14, 379-388. doi:10.1097/01.pra.0000341892.51124.85

Teachman, B. A. (2007). Evaluating implicit spider fear associations using the Go/No-go Association Task. Journal of Behavior Therapy and Experimental Psychiatry, 38, 156-167. doi:10.1016/j.jbtep.2006.10.006

Thornton, D., \& Laws, D. R. (2009). Cognitive approaches to the assessment of sexual interest in sexual offenders. West Sussex, UK: Wiley Blackwell.

Ward, T., \& Beech, A. (2006). An integrated theory of sexual offending. Aggression and Violent Behavior, 11, 44-63. doi:10.1016/j.avb.2005.05.002

Williams, B. J., \& Kaufmann, L. M. (2012). Reliability of the Go/No Go association task. Journal of Experimental Social Psychology, 48, 879-891. doi:10.1016/j.jesp.2012.03.001

Wilson, G. D. (1978). The secrets of sexual fantasy. London: J.M. Dent \& Sons.

Wurtele, S. K., Simons, D., \& Moreno, T. (2014). Sexual interest in children among an online sample of men and women: Prevalence and correlates. Sexual Abuse: A Journal of Research and Treatment, 26, 546-568. doi:10.1177/1079063213503688 
Critical and distracter words used for the Sexual Fantasy-GNAT and control GNAT

\section{Sexual Fantasy-GNAT Control GNAT}

\begin{tabular}{llll}
\hline Sexual Fantasy & Matched Distracter & Toy & Matched distracter \\
\hline Sex & Sit & Teddy & Tangy \\
Orgy & Oven & Yoyo & Yolk \\
Blowjob & Blended & Lego & Lens \\
Bondage & Bombing & Dolly & Dirty \\
Threesome & Textbooks & Frisbee & Fallacy \\
Fetish & Fading & Marbles & Margins \\
Naked & Navel & Barbie & Barley \\
Spanking & Skipping & Football & Feedback \\
Orgasm & Orange & Slinky & Sleepy \\
Ejaculate & Easygoing & Dollhouse & Doorbells \\
Stripping & Screening & Dominoes & Drawback \\
Anal & Atom & Skateboard & Straighten \\
Whipping & Whirling & Playstation & Progressive \\
Doggystyle & Documented & Jigsaw & Jagged \\
Foreplay & Foregone & Kite & Keel \\
\hline
\end{tabular}


Table 1: Demographic, offense, and risk-related information for the extrafamilial ISOCs, intra/mixed ISOCs, and non-offenders

\begin{tabular}{|c|c|c|c|c|}
\hline Variable & $\begin{array}{c}\text { Extrafamilial } \\
(\mathrm{EF}) \\
(n=29)\end{array}$ & $\begin{array}{c}\text { Intra/mixed } \\
(\mathrm{I} / \mathrm{M}) \\
(n=15)\end{array}$ & $\begin{array}{c}\text { Non- } \\
\text { offenders } \\
(n=26)\end{array}$ & $\begin{array}{l}\text { EF vs. I/M } \\
\text { comparisons } \\
\text { (Cohen's } d \text { ) }\end{array}$ \\
\hline \multicolumn{5}{|l|}{ Ethnicity } \\
\hline Caucasian & $86 \%$ & $67 \%$ & $81 \%$ & \\
\hline Black & $7 \%$ & $27 \%$ & $0 \%$ & \\
\hline N. American & $3 \%$ & $7 \%$ & $0 \%$ & \\
\hline Asian & $3 \%$ & $0 \%$ & $8 \%$ & \\
\hline Other & $0 \%$ & $0 \%$ & $11 \%$ & \\
\hline \multicolumn{5}{|c|}{$\begin{array}{l}\text { Relationship status: } \\
\text { In a relationship }\end{array}$} \\
\hline Single & $3 \%$ & $0 \%$ & $35 \%$ & \\
\hline Divorced & $69 \%$ & $73 \%$ & $65 \%$ & \\
\hline Widowed & $24 \%$ & $27 \%$ & $0 \%$ & \\
\hline & $3 \%$ & $0 \%$ & $0 \%$ & \\
\hline \multicolumn{5}{|l|}{$M_{\text {age }}(S D)$ at first } \\
\hline sexual offense $^{\mathrm{a}}$ & $18(5.72)$ & $18(5.52)$ & $\mathrm{n} / \mathrm{a}$ & 0.07 \\
\hline \multicolumn{5}{|l|}{ Victim gender: } \\
\hline Male & $31 \%$ & $6.7 \%$ & $\mathrm{n} / \mathrm{a}$ & 0.57 \\
\hline Female & $24.1 \%$ & $80 \%$ & $\mathrm{n} / \mathrm{a}$ & 1.27 \\
\hline Both & $44.8 \%$ & $13.3 \%$ & $\mathrm{n} / \mathrm{a}$ & 0.66 \\
\hline
\end{tabular}

Offense history:

$\begin{array}{lllll}\text { Prior sexual } & 89.7 \% & 93.3 \% & \mathrm{n} / \mathrm{a} & 0.12\end{array}$

$\begin{array}{lllll}\text { Prior violent } & 20.7 \% & 40.0 \% & \mathrm{n} / \mathrm{a} & 0.42\end{array}$

Prior non-violent, $\quad 44.8 \% \quad 66.7 \% \quad$ n/a $\quad 0.14$ non-sexual

$\begin{array}{lllll}\text { Static-99R }-M(S D)^{\mathrm{b}} & 5.6(1.2) & 5.8(1.9) & \mathrm{n} / \mathrm{a} & 0.12\end{array}$

Note. ${ }^{\text {a }} n=1$ extrafamilial participant missing data. ${ }^{b} n=1$ extrafamilial participant missing data. $* *=p<.001, *=p<.05$ 
Table 2: Differences between groups on each block and mean difference score for both the Sexual Fantasy-GNAT and Control-GNAT

\begin{tabular}{|c|c|c|c|c|c|c|}
\hline Measure & $\begin{array}{c}\text { Extrafamilial } \\
n=29\end{array}$ & $\begin{array}{c}\text { Intra/Mixed } \\
n=15\end{array}$ & $\begin{array}{c}\text { Non-offender } \\
n=25\end{array}$ & EF vs. I/M & EF vs. NO & $\mathrm{I} / \mathrm{M}$ vs. NO \\
\hline & $M(S D)$ & $M(S D)$ & $M(S D)$ & $d(95 \% \mathrm{CI})$ & $d(95 \% \mathrm{CI})$ & $d(95 \% \mathrm{CI})$ \\
\hline \multicolumn{7}{|l|}{ Fantasy-GNAT } \\
\hline Adult block (ms) & $637.74(88.57)$ & $626.89(112.55)$ & $608.31(58.55)$ & $-0.11(-0.74,0.51)$ & $-0.39(-0.93,0.15)$ & $-0.23(-0.87,0.42)$ \\
\hline \multicolumn{7}{|l|}{ Toy-GNAT } \\
\hline Child block (ms) & $593.28(65.07)$ & $651.62(134.81)$ & $622.59(68.79)$ & $0.62(-0.02,1.26)$ & $0.44(-0.10,0.98)$ & $=0.29(-0.94,0.35)$ \\
\hline Adult block (ms) & $641.99(83.38)$ & $662.84(126.52)$ & $644.27(79.92)$ & $0.21(-0.42,0.83)$ & $0.03(-0.51,0.56)$ & $=0.19(-0.83,0.46)$ \\
\hline Mean difference & $48.71(72.01)$ & $1.90(90.11)$ & 32.67 (77.94) & $=0.59(-1.23,0.04)$ & $-0.21(-0.75,0.32)$ & $0.37(-0.27,1.02)$ \\
\hline
\end{tabular}

Note. $\mathrm{EF}=$ Extrafamilial, $\mathrm{I} / \mathrm{M}=\mathrm{Intra} / \mathrm{Mixed}, \mathrm{NO}=$ Non-offender. $* p<.01$ 
Table 3: Spearman's Rho Correlations between Sexual Fantasy-GNAT outcomes and self-reported sexual fantasies

\begin{tabular}{|c|c|c|c|c|c|c|}
\hline Measure & 1 & 2 & 3 & 4 & 5 & 6 \\
\hline 1. Child block & - & & & & & \\
\hline 2. Adult block & $.64 * * *$ & - & & & & \\
\hline 3. Mean difference & $-.41 * * *$ & $.37 * *$ & - & & & \\
\hline $\begin{array}{l}\text { 4. Sexual fantasies } \\
\text { about children }^{\mathrm{a}}\end{array}$ & .06 & .14 & $.31 *$ & - & & \\
\hline $\begin{array}{l}\text { 5. Seducing an } \\
\text { innocent (WSFQ) }\end{array}$ & -.01 & .01 & .03 & $.40 * *$ & - & \\
\hline $\begin{array}{l}\text { 6. Sex with } \\
\text { someone much } \\
\text { younger (WSFQ) }\end{array}$ & -.04 & .05 & .15 & $.62 * * *$ & $.51 * * *$ & \\
\hline $\begin{array}{l}\text { 7. Impersonal } \\
\text { subscale (WSFQ) }\end{array}$ & -.11 & $-.26^{*}$ & -.21 & $-.28 *$ & $.57 * * *$ & $.47 * * *$ \\
\hline $\begin{array}{l}\text { 8. Intimate subscale } \\
\text { (WSFQ) }\end{array}$ & -.21 & -.17 & -.01 & -.14 & $.38 * *$ & .16 \\
\hline $\begin{array}{l}\text { 9. Sadomasochistic } \\
\text { subscale (WSFQ) }\end{array}$ & -01 & -.20 & $-.26^{*}$ & -.15 & $.40 * *$ & .20 \\
\hline $\begin{array}{l}\text { 10. Exploratory } \\
\text { subscale (WSFQ) }\end{array}$ & -.11 & -.10 & -.01 & $-.31 *$ & $.59 * * *$ & $.35^{*}$ \\
\hline
\end{tabular}

$*=p<.05, * *=p<.01, * * *=p<.001$

Note: ${ }^{a}$ Point-biserial correlation as dichotomous and continuous data were used.

WSFQ = Wilson Sex Fantasy Questionnaire 